\title{
Respirable inorganic fibers dispersed in air and settled in human lung samples: assessment of their nature, source, and concentration in a NW Italy large city
}

\author{
Silvana CAPELla ${ }^{1}$, Elena Belluso ${ }^{1}$, Donata \\ BELLIS $^{1,2}$, ElENA FioretTI ${ }^{3}$, Roberto MARINELli ${ }^{4}$
}

${ }^{1}$ Department of Earth Sciences, Interdepartmental Centre for Studies and other Toxic Particulates "G. Scansetti", University of Torino, Torino, Italy

${ }^{2}$ Department of Surgery, Pathological Anatomy, Ospedale degli Infermi, Ponderano, Biella, Italy

${ }^{3}$ Strada Bussolino 68, 10090 - Gassino Torinese, Italy

${ }^{4}$ Via Parma 11/C, 39100 - Bolzano, Italy

The present investigation represents a new approach useful to evaluate the general population risk correlated with environmental exposure to air dispersed inorganic fibers. The used method is based on the evaluation of the respirable inorganic fibers both air dispersed in a big city and contained in lungs of the general population following their respiration. Moreover, these data allow to identify the sources of dispersion (anthropogenic or natural) in air of the inorganic fibers and therefore to apply strategies to improve air quality. To describe this approach, the authors investigated air samples from a big city in NW Italy and lung inorganic burden of people here lived. This paper reports the data of the airborne inorganic fibers detected in two sampling campaign (2014 and 2016), in 24 districts of Torino (Piemonte, NW Italy), and in some autoptic lungs of general population lived here. The airborne fibers were characterized by scanning electron microscopy (SEM) with annexed energy dispersive spectroscopy (EDS). The identified inorganic fiber species were assigned to 5 groups among which tremolite/actinolite asbestos. They are dispersed from natural sources (i.e. certain kinds of rocks outcropping in the city surrounding areas). In no-one of the 24 districts of Torino their concentration highlighted a situation of asbestos pollution in place.

A correlation with inorganic fibers (characterized by SEMEDS) detected in lung tissue samples of 10 subjects lived in Torino all their life and without professional exposure to asbestos were attempted. The only types of fibers identified as asbestos are tremolite/actinolite asbestos, and they match those detected in air sampling. The number of fibers per 1 gram of tissue dry weight is lower than the quantities reported as indicative of significant asbestos exposure. We observed interesting gender differences. 